\title{
ATTEMPT OF ALPINE GLACIER FLOW MODELING BASED ON CORRELATION MEASUREMENTS OF HIGH RESOLUTION SAR IMAGES
}

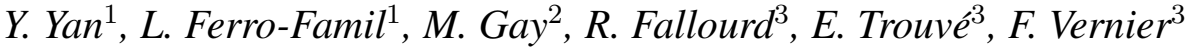 \\ 1:IETR, CNRS, Université de Rennes 1, France \\ yajing.yan@ulg.ac.be, laurent.ferro-famil@univ-rennes1.fr \\ 2:Gipsa-lab, CNRS, Université de Grenoble, France \\ michel.gay@gipsa-lab.grenoble-inp.fr \\ 3:LISTIC, Université de Savoie, Polytech Annecy-Chambéry, France \\ emmanuel.trouve|renaud.fallourd|flavien.vernier@univ-savoie.fr
}

\begin{abstract}
In this paper, an attempt of Alpine glacier flow modeling is performed based on a series of high resolution TerraSAR-X SAR images and a Digital Elevation Model. First, a glacier flow model is established according to the fluid mechanics theory in a simplified framework. Second, the displacement field over the glacier obtained from the sub-pixel image correlation of a series of TerraSAR-X SAR images is used to refine the model obtained previously. The comparison between the data observation and the model prediction allows for the validation of the established model. According to the obtained results, despite the simplifications made in the modeling, the established glacier flow model can provide general satisfactory results. Further investigation and improvement of this glacier flow model seem promising.
\end{abstract}

Index Terms - Alpine glacier flow modeling, high resolution SAR images

\section{INTRODUCTION}

The monitoring of the Alpine glacier flow evolution is of great importance, since this evolution has important consequences in terms of water resources, economical development and risk management in the surrounding areas [1,2]. Many in-situ instruments such as GPS, digital cameras, have been installed in order to follow the glacier flow evolution. However, these installations are usually limited by the difficult access to many glacier areas and the expensive maintenance in glacier areas. In the recent years, the remote sensing data acquired by air-borne or space-borne sensors are largely used in complement to in-situ measurements, which allows regular dense measurements of glacier displacement to be performed over large area $[2,3,4,5]$. The latter is crucial for significant change detection of some physical parameters, as well as for glacier flow model constrain. However, because of the surface property change (snowfalls, etc.), these remote sensing measurements cannot be obtained everywhere on the glacier. For some glaciers, typically the Argentière glacier, lack of reliable measurements is present over large area $[2,6]$.

The progress on the knowledge of the mechanical properties of ice makes the glacier flow modeling possible. In the 1950s, the glacier flow theory has already been established and re-examined later with the improvement of the mechanical property knowledge [7]. In [8], several models have been proposed and compared. However, there is no glacier flow model completely operational nowadays, due to lack of complete knowledge of the mechanical properties and the structures of the glacier. On the other hand, the lack of complete, regular and precise measurements of the surface displacement field and some crucial physical parameters such as the thickness, the viscosity, the basal sliding velocity, hinders also the constrain of glacier flow modeling. Despite these difficulties, some effort has been made in order to understand the machanism of the glacier flow in the glaciology community. The shallow ice approximation appears to be the most widely used method, because of its simplicity [9].

In the context of increasing availability of remote sensing measurement for glacier flow monitoring, especially the availability of high resolution SAR images, the combination of the fluid mechanics theory and the glacier flow measurement allows for, on the one hand, the construction of the glacier flow model with not only the fluid mechanics theory, but also the data observation constrain; on the other hand, the complementarity to the lack of measurements over certain areas of the glacier. In this paper, an attempt of glacier flow modeling is carried out based on the shallow ice approximation, a series of high resolution TerraSAR-X SAR images acquired in summer of 2009 (Table 1) and a high resolution Digital Elevation Model (DEM). The attempt is performed over the Argentière glacier. The objective is firstly to derive a simplified mathmatical glacier flow model based on fluid mechanics theory, and secondly to determine some parameters of the model obtained previously according to the measurements. The vali- 
dation of the model is carried out through the comparison of the displacement field between the model prediction and the measurement observation.

This paper is organised as follows: a short description of the high resolution TerraSAR-X SAR data and the DEM is given in section 2. Moreover, in this section, an hypothesis of the relationship between the glacier flow direction and the largest slope direction for the modeling is verified using the SAR data and the DEM. In section 3, the construction and the validation of the glacier flow model using the displacement observations from sub-pixel image correlation of TerraSAR$\mathrm{X}$ SAR images are present in detail. Finally, the conclusion and the future work are derived in section 4 .

\section{DATA}

A series of high resolution TerraSAR-X SAR images, acquired in the summer of 2009, are available for displacement measurement over the Argentière glacier (Table 1). The subpixel image correlation is applied to these images in order to retrieve the displacement in range and azimuth directions of each acquisition over the glacier, from which the mean glacier flow velocity over each time period spanned by the SAR image pairs are obtained. Associated with the displacement measurement, a confidence parameter varing between 0 and 1 , which corresponds to the correlation peak is provided in order to indicate the reliability of the obtained measurement. This confidence parameter is important, since the higher the confidence parameter, the larger the contribution of the measurement to the glacier flow model constrain. Moreover, a DEM with resolution of $4 \mathrm{~m}$ is available to derive the slope over the glacier.

\begin{tabular}{||c|c|c||}
\hline \hline Orbit direction & Acquisition date & Time period (days) \\
\hline \hline \multirow{4}{*}{ Descending } & $2009-05-29-2009-06-09$ & 11 \\
\cline { 2 - 4 } & $2009-06-09-2009-06-20$ & 11 \\
\cline { 2 - 4 } & $2009-06-20-2009-07-01$ & 11 \\
\cline { 2 - 4 } Ascending & $2009-07-01-2009-07-12$ & 11 \\
\hline \multirow{4}{*}{} & $2009-05-31-2009-06-11$ & 11 \\
\cline { 2 - 4 } & $2009-06-11-2009-06-22$ & 11 \\
\cline { 2 - 3 } & $2009-06-22-2009-07-03$ & 11 \\
\cline { 2 - 3 } & $2009-07-03-2009-07-14$ & 11 \\
\hline \hline
\end{tabular}

Table 1. List of TerraSAR-X SAR datasets.

The first hypothesis of the glacier flow modeling relies on that the glacier flows along the direction of the largest slope. To verify this hypothesis, on the one hand, the direction of the largest slope is calculated from the DEM. On the other hand, the direction of the glacier flow is estimated from the displacement in range and azimuth directions obtained from correlation measurements. According to Figure 1, there is a pretty good agreement between the direction of the largest slope and the direction of the glacier flow displacement in the Northern part. In the Southern part, the displacement measurement from the sub-pixel correlation is very noisy because of coherence loss. As a result, the displacement measured in this part is not reliable. From Figure 1, the hypothesis made on the direction of the glacier flow can be verified. Thereafter, in the modeling, the glacier flow velocity, $v$, is assumed to be in the direction of the largest slope, $\theta$.

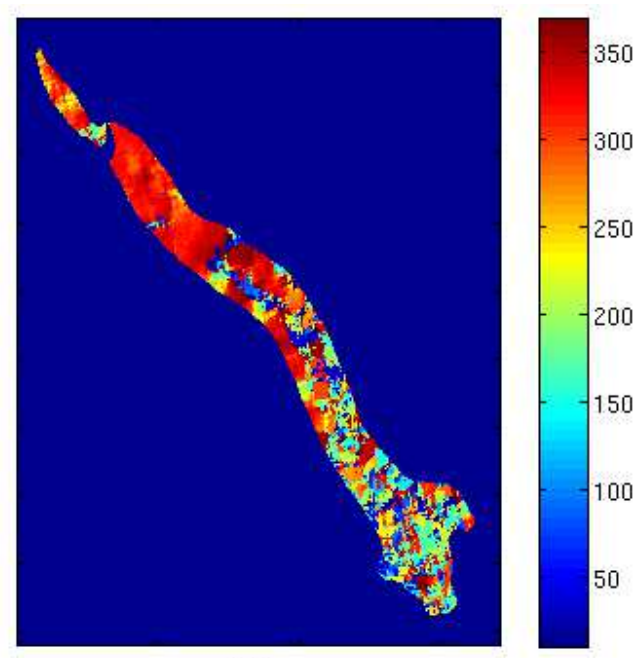

(a)

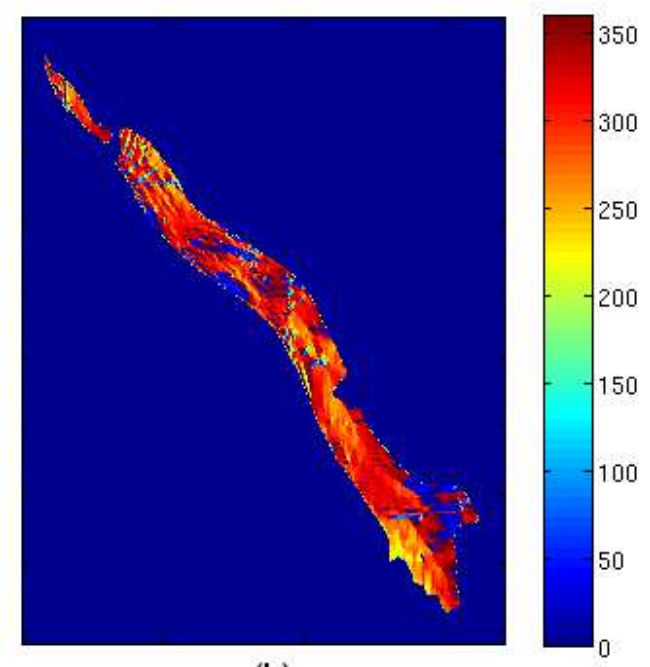

(b)

Fig. 1. (a) Azimuth of glacier flow calculated from the correlation measurements (b) Azimuth of the largest slope obtained from the DEM. (clockwise from the North)

\section{GLACIER FLOW MODELING}

Consider a simple case where the ice flows on an inclined bedrock with $\theta$ as slope (Figure 2 (a)), according to the shal- 
low ice equations [9], the velocity as a function of the height of ice $z$ can be expressed as follows:

$$
v(z)=\frac{2 A}{n+1}(\rho g \sin \theta)^{n}\left(h^{n+1}-(h-z)^{n+1}\right)+v_{b}
$$

where $\rho$ denotes the density of ice, $h$ represents the thickness of the ice, $v_{b}$ denotes the basal sliding velocity, $g$ is the gravitational acceleration and $A$ is an empirical coefficient.

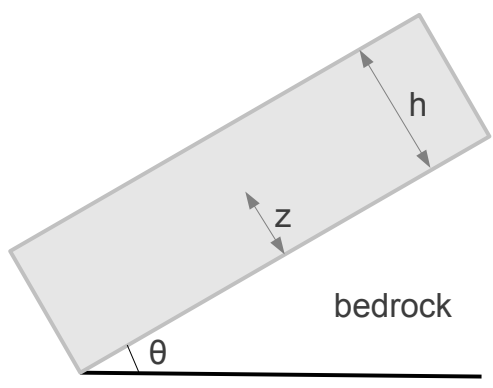

(a)

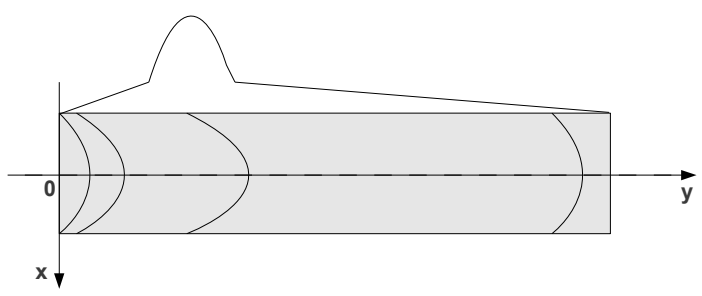

(b)

Fig. 2. (a) Illustration of the geometry of the glacier flow model (b) Illustration of the parabolic constrain.

At the surface of the glacier, $z=h$, thus the velocity at the surface is given by:

$$
v_{\text {surf }}=\frac{2 A}{n+1} h(\rho g h \sin \theta)^{n}+v_{b}
$$

The basal sliding velocity $v_{b}$ is unknown, and there is no efficient means for its measurement, for sake of simplicity, it is considered as constant in this paper.

According to numerous measurements [2,6], the front of the glacier flow is in parabolic shape. In each line perpendicular to the flow direction, the variation of the velocity from the center to the periphery can be modeled by a parabolic function (Figure 2 (b)). Therefore, on each line perpendicular to the flow direction, if the velocity in the center is known, the velocities at other positions can be deduced from this parabolic relationship. Consider that the velocity in the center of each line perpendicular to the glacier flow direction can be estimated from equation 2, a parabolic constrain is thus added to equation 2 in order to retrieve the velocity at any other point on the same line.

$$
v_{\text {surf }}=\frac{2 A}{n+1} h(\rho g h \sin \theta)^{n}-\frac{B \rho g \sin \theta}{2 \eta} x^{2}+v_{b}
$$

$B$ is a coefficient for constrain weighting. $x$ corresponds to the distance from the point under consideration to the center point on each line perpendicular to the flow direction (Figure $2(b)) . \eta$ is the dynamic viscosity.

In usual assumptions, $n=3[7,10]$, thus

$$
v_{\text {surf }}=\frac{A}{2} h(\rho g h \sin \theta)^{3}-\frac{B \rho g \sin \theta}{2 \eta} x^{2}+v_{b}
$$

According to equation 4, the velocity of the glacier flow at the surface depends on the largest slope, the dynamic viscosity and the thickness of ice, assuming that the density of glacier is constant. Indeed, the thickness and the dynamic viscosity of the glacier vary depending on the position and the temperature. However, there is no precise measurements available here. In the first approximation, they are considered constant for the whole glacier, $400 \mathrm{~m}$ and $1.0 \times 10^{7}$ Po respectively. Then, to derive the glacier flow velocity, we have two coefficients $A$ and $B$ to determine. For this, we use the correlation measurements of SAR images. The estimation of $A$ and $B$ is performed by minimising the difference between the model prediction and the measurement observation in weighted least squares sense. The weight is issued from the confidence parameter associated with the displacement value in the correlation computation. Note that in the case of the Argentière glacier, the correlation measurements are only available in the Northern part, $A$ and $B$ are estimated using measurements in this part.

An example of the Argentire glacier flow velocities estimated from the correlation measurements and simulated from the model is shown in Figure 3. The displacement field predicted by the model is smoother than that obtained from the measurement, since the modeled displacement field is not subject to noise. In the Northern part where the measurement is available, the model predicts well the velocity peak. Therefore, it is able to reveal the main features of the displacement, despite the simplifications of the glacier geometry and the mechanical parameters used in the model.

\section{CONCLUSIONS}

According to Figure 3, this data-based glacier flow modeling is promising. Despite its simplicity, it can capture the main features of the displacement and provide generally satisfactory glacier flow displacement field. Especially in areas without measurement, displacement information can be obtained according to the prediction of this simple model, which is important for the glacier flow monitoring. Although the parameters used in the modeling are specific for the Argentière 
(a)

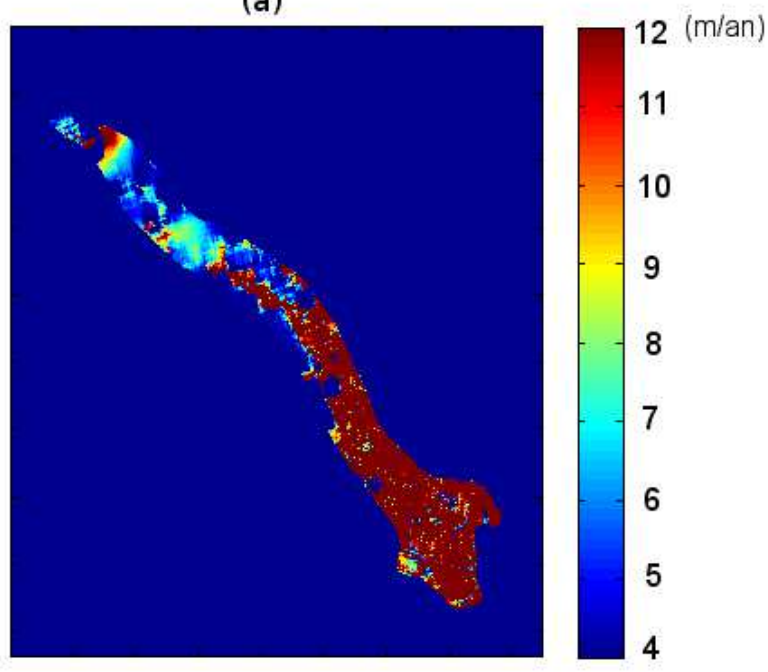

(b)

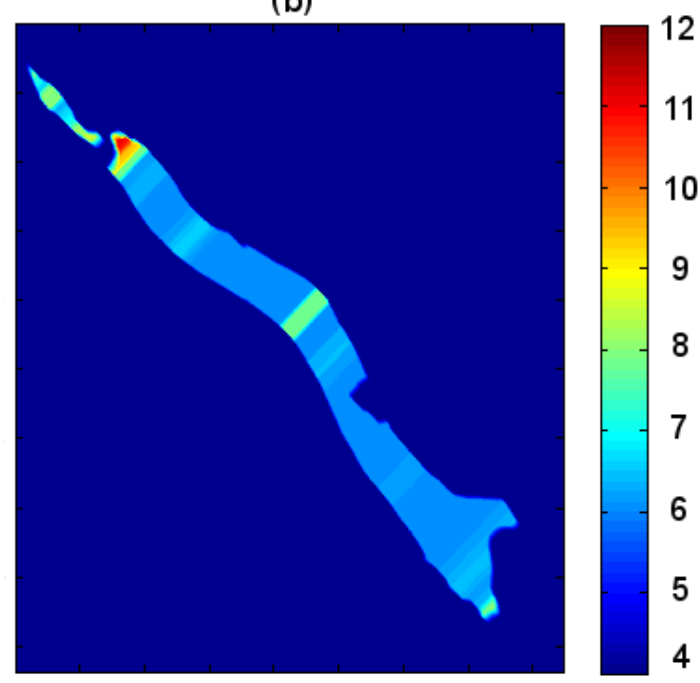

Fig. 3. Argentière glacier flow velocity of the period of 200905-29 - 2009-06-09 (a) estimated from correlation measurements (b) predicted by the glacier flow model.

glacier, the approach can be applied to other glaciers with appropriate parameters. Using measurements obtained at different periods, we can further estimate the seasonal variation of the glacier flow velocity by tuning the two coefficients $A$ and $B$, which constitutes the future work. Furthermore, using GPS measurements available in the Southern part to validate further the model prediction will also be taken into consideration.

\section{ACKNOWLEDGMENTS}

This work was supported by the EFIDIR project (ANR-07MDCO-004) (http://www.efidir.fr) granted by the French Na- tional Agency (ANR). The authors wish to thank the ANR for their support.

\section{REFERENCES}

[1] F. Vernier, R. Fallourd, J. M. Friedt, Y. Yan, E. Trouvé, J.M. Nicolas, and L. Moreau. Fast Correlation Technique for Glacier Flow Monitoring by Digital Camera and Space-borne SAR Images. EURASIP Journal on Image and Video Processing, 2011.

[2] R. Fallourd, O. Harant, E. Trouvé, J.-M. Nicolas, M. Gay, A. Walpersdorf, J.-L. Mugnier, J. Serafini, D. Rosu, L. Bombrun, G. Vasile, N. Cotte, F. Vernier, F. Tupin, L. Moreau, and P. Bolon. Monitoring Temperate Glacier Displacement by Multi-Temporal TerraSAR-X Images and Continuous GPS Measurements. IEEE Journal of Selected Topics in Applied Earth Observations and Remote Sensing, 4(2):372-386, 2011.

[3] K.E. Mattar, P.W. Vachon, D. Geudtner, A.L. Gray, I.G. Cumming, and M. Brugman. Validation of Alpine Glacier Velocity Measurements Using ERS TandemMission SAR Data. IEEE Transactions on Geoscience and Remote Sensing, 36(3):974 - 984, 1998.

[4] E. Berthier, Y. Arnaud, D. Baratoux, C. Vincent, and F. Rémy. Recent rapid thinning of the "mer de glace" glacier derived from satellite optical images. Geophysical Research Letters, 31(17):L17401, 2004.

[5] O. Harant, L. Bombrun, G. Vasile, L. Ferro-Famil, and M. Gay. Displacement Estimation by Maximum Likelihood Texture Tracking. IEEE Journal of Selected Topics in Signal Processing, 5(3):398-407, 2011.

[6] E. Berthier, H. Vadon, D. Baratoux, Y. Arnaud, C. Vincent, K. Feigl, F. Rémy, and B. Legrésy. Mountain glaciers surface motion derived from satellite optical imagery. Remote Sensing of Environment, 95(1):14-28, 2005.

[7] J.F. Nye. The mechanics of glacier flow. Journal of Glaciology, 2(12):82-93, 1952.

[8] M. Schafer. Modélisation de l'écoulement des glaciers tempérés. PhD thesis, Universit Joseph Fourier, 2007.

[9] E. Le Meur, O. Gagliardini, T. Zwinger, and J. Ruokolainen. Glacier flow modelling: a comparison of the Shallow Ice Approximation and the full-Stokes solution. C.R. Physique, 5:709-722, 2004.

[10] J.W. Glen. Experiments on the deformation of ice. Journal of Glaciology, 2(12):111-114, 1952. 